\title{
Studies on Pollen Germination, Pollination and Fruit Set in Raspberry (Rubus ellipticus) under Hilly Conditions of Uttarakhand
}

\author{
Neema Pawar ${ }^{1}$, Nidhika Thakur ${ }^{1 *}$, Manju Negi ${ }^{1}$ and Ajay Paliwal ${ }^{2}$ \\ ${ }^{1}$ Department of Fruit Science, ${ }^{2}$ Department of Genetics and Plant Breeding, VCSG, UUHF, \\ Bharsar, Pauri Garhwal, U.K., India \\ *Corresponding author
}

\begin{tabular}{|c|c|}
\hline & \multirow{5}{*}{$\begin{array}{l}\text { The pollen grains of raspberry exhibited the average size (length } \mathrm{x} \text { width) of } \\
177.73 \times 124.43 \mu \text { in glycerol conditions, followed by }(173.29 \times 173.29 \mu) \text { in water } \\
\text { suspension. The viability of fresh pollen grains ranged from } 32.50 \% \text { to } 97.70 \% \text { in } \\
\text { hermaphrodite or bisexual flowers. } 25 \% \text { sucrose solution }+0.4 \% \text { boric acid } \\
\text { solution showed the highest pollen germination of } 36.66 \% \text { with the maximum } \\
\text { pollen tube length }(284.37 \mu) \text { after } 48 \text { hours interval. After } 3 \text { days storage, the } \\
\text { pollen grains were quite normal and showed } 46.66 \% \text { germination. The longevity } \\
\text { of pollen grains stored under room conditions indicated that on the third day of } \\
\text { storage, the pollen grains were quite normal and showed } 97.70 \% \text { germination. But } \\
\text { after that the longevity of pollen decreased rapidly and after } 9 \text { days of storage, the } \\
\text { viability dropped to nill. The stigmas were } 86.66 \% \text { receptive on the day of } \\
\text { anthesis. Bag self-pollination resulted in the highest fruit set }(96.66 \%) \text { as } \\
\text { compared to hand self-pollination and open pollination. }\end{array}$} \\
\hline & \\
\hline & \\
\hline & \\
\hline & \\
\hline
\end{tabular}

\section{Introduction}

The Himalayan yellow raspberry (Rubus ellipticus var. obcordatus) is a large, thorny perennial shrub with heavily armed upright canes (Stratton, 1996). The genus Rubus is one of the largest genera of the family Rosaceae, consisting of more than 750 species. Focke (1910) divided this variable and taxonomically complex genus into $12 \mathrm{sub}$ genera. At present, the area, production and productivity in India is completely negligible. Raspberries have a wide range of medicinal and nutritional property. Even though raspberry is used widely in preparation of post-harvest products like jam, jelly etc, but it is not under commercial cultivation in India. It is due to poor knowledge about raspberry that Indian farmers do not cultivate it and rural folks exploit it from the wild. Proper knowledge about flowering and bearing habit of raspberry will contribute in its cultivation efforts. There is little literature about its flowering and fruit set in India, therefore, to enlighten this part of raspberry cultivation present study was conducted. The aim of the present study was to investigate the floral and reproductive biology of Rubus ellipticus examining the implications of floral biology and breeding systems on its life cycle. Alternatively, it is expected to give information which would be useful in management strategies for protecting its endangered population. 


\section{Materials and Methods}

A field experiment was carried out at VCSG College of Horticulture, Bharsar, Pauri Garhwal, Uttarakhand during 2015 - 2016. The experiment of pollen study of raspberry required dissection box, butter paper, tag, light microscope, glassware, standardized ocular, stage micrometer and chemicals used for different media and other operations.

\section{Results and Discussion}

\section{Pollen size in different media}

The pollen grains of raspberry exhibited the average size (length $x$ width) of $177.73 \mathrm{x}$ $124.43 \mu$ in glycerol conditions, followed by $173.29 \times 173.29 \mu$ in water suspension. The minimum size of pollen grains $168.84 \mathrm{x}$ $133.31 \mu$ was recorded under the dry conditions, followed by acetocarmine staining $(146.63 \times 146.63 \mu)$. The shape of pollen grains in glycol and dry conditions were oblong, elliptic and in acetocarmine and water pollen grains looked round in shape. Bisht and Sharma (1986) found that the fresh pollen grains of apple were elliptic and tricolpate and in acetocarmine solution the pollen grains assumed triangular shape. The average length of fresh pollens ranged from 33.96 to $47.95 \mu$ in different cultivar, whereas the breadth ranged from 23.97 to $29.97 \mu$. The average length and breadth of pollen grain in aniline oil ranged from 38.29 to $47.95 \mu$ and 21.31 to $26.64 \mu$ respectively in some apple cultivars. Ali (1962) and Chauhan (1966) observed that the shape of the pollen grains in dry state was elliptical. While the shape of the pollen grains was observed to be roundish when mounted in $2 \%$ acetocarmine.

\section{Pollen viability}

The viability of fresh pollen grains was estimated by acetocarmine test. The pollen grains staining deeply and looking normal under several microscopic fields were counted as viable, whereas shriveled and poorly stained were considered as non-viable. Raspberry viability of fresh pollen grains ranged from $32.50 \%$ to $97.70 \%$ in hermaphrodite or bisexual flowers. Gercekcioglu et al., (2000) studied the pollen grains of eight different pome and stone fruit cultivars (plum, peach, sweet cherry and apple cultivars) and observed pollen viability in the range of 71.53 to 81.78 per cent. Otterbacher et al., (1983) showed that high temperature resulted in rapid loss of viability of raspberry pollen (Table 2).

\section{Pollen germination}

The pollen grains were planted in artificial sucrose media $(10,15,20$ and $25 \%)$ and different boric acid solution (0.1, 0.2, 0.3 and $0.4 \%)$. Distilled water served as a control. Slides have been examined at 12, 24 and 48 hours after planting the pollen grains in different media and observation and pollen tube length were recorded at least under different microscopic fields in each medium.

It is evident from table 1 that $25 \%$ sucrose solution $+0.4 \%$ boric acid media was recorded to show the maximum pollen germination of $36.66 \%$ and pollen tube length $(284.37 \mu)$ after 48 hours, followed by $25 \%$ sucrose solution with $25.00 \%$ germination and $(253.27 \mu)$ pollen tube length. The control showed the minimum pollen germination of $4.33 \%$ with $(13.33 \mu)$ pollen tube length after 48 hours (Table 1 ).

Similar observations were recorded by the Asma (2008) who studied the pollen viability and germination ratios for eight apricot cultivars. The results indicated that viable, semi viable and dead pollen rates differed among cultivars. Amongst the four concentration of sucrose solution studied, best 
pollen grain germination was obtained with $25 \%$ sucrose solution $+0.4 \%$ boric acid solution which ranged from 9.66 to $36.66 \%$. Similar observations were recorded by Wertheim (1996) who reported that 13 to 89 $\%$ pollen germination took place in different apple cultivars in a solution containing $15 \%$ sucrose $+15 \mathrm{ppm}$ boric acid $+150 \mathrm{ppm}$ calcium nitrate.

Kumar (1996) reported that the sucrose solution of 9 to $10 \%$ was reported to be the most effective for pollen germination of apple cultivars. Abdel (1999) reported 73.30 to 86.10 per cent pollen germination with $15 \%$ sucrose solution in three apple cultivars. The best pollen tube length $(284.37 \mu)$ was observed with $25 \%$ sucrose $+0.4 \%$ boric acid solution at 48 hours interval.

\section{Pollen longevity}

For longevity study, fresh pollen grains were stored in dry petri dishes and maintained at room conditions without controlling the humidity.

The longevity of pollen grains stored under room conditions indicated that on the third day of storage, the pollen grains were quite normal and showed $97.70 \%$ germination. But after that the longevity of pollen decreased rapidly and after 9 days of storage, the viability dropped to nill (Table 2).

Table.1 Pollen germination and pollen tube growth of raspberry in different media

\begin{tabular}{|c|c|c|c|c|c|c|}
\hline \multirow[t]{2}{*}{ Treatment } & \multicolumn{3}{|c|}{ Percentage of pollen germination $(\%)$} & \multicolumn{3}{|c|}{ Pollen tube length $(\mu)$} \\
\hline & 12 hours & 24 hours & 48 hours & 12 hours & 24 hours & 48 hours \\
\hline$T_{1-}-10 \%$ sucrose solution & 8.33 & 13.00 & 20.66 & 62.20 & 26.66 & 48.87 \\
\hline$T_{2-1}-15 \%$ sucrose solution & 6.33 & 14.00 & 22.00 & 44.43 & 48.87 & 137.74 \\
\hline $\begin{array}{lll}\mathbf{T}_{3^{-}} \quad 20 & \% & \text { sucrose } \\
\text { solution } & & \end{array}$ & 7.66 & 15.66 & 21.66 & 66.65 & 44.43 & 133.30 \\
\hline$T_{4}-25 \%$ sucrose solution & 8.66 & 19.33 & 25.00 & 88.86 & 159.96 & 253.27 \\
\hline$T_{5}-0.1 \%$ boric acid & 4.66 & 9.00 & 17.00 & 31.10 & 13.33 & 31.10 \\
\hline$T_{6}-0.2 \%$ boric acid & 5.33 & 10.00 & 11.33 & 31.10 & 17.77 & 48.87 \\
\hline$T_{7}-0.3 \%$ boric acid & 5.33 & 11.33 & 11.33 & 17.77 & 13.33 & 26.66 \\
\hline$T_{8^{-}} 0.4 \%$ boric acid & 6.00 & 12.00 & 9.66 & 35.54 & 31.10 & 35.54 \\
\hline $\begin{array}{l}T_{9-}-10 \% \text { sucrose solution } \\
+0.1 \% \text { boric acid }\end{array}$ & 7.00 & 11.66 & 14.00 & 26.66 & 57.76 & 53.32 \\
\hline $\begin{array}{l}\mathrm{T}_{10^{-}} \quad 15 \% \quad \text { sucrose } \\
\text { solution }+0.2 \% \text { boric } \\
\text { acid }\end{array}$ & 8.00 & 16.00 & 17.66 & 44.43 & 84.42 & 57.76 \\
\hline $\begin{array}{l}\mathrm{T}_{11^{-}} \quad 20 \% \quad \text { sucrose } \\
\text { solution }+0.3 \% \text { boric } \\
\text { acid }\end{array}$ & 7.33 & 17.00 & 24.66 & 57.76 & 53.32 & 133.30 \\
\hline $\begin{array}{l}\mathrm{T}_{12^{-}} \quad 25 \% \quad \text { sucrose } \\
\text { solution }+0.4 \% \text { boric } \\
\text { acid }\end{array}$ & 8.66 & 20.00 & 36.66 & 88.86 & 168.84 & 284.37 \\
\hline$T_{13^{-}}$(control) Water & 0.00 & 0.00 & 4.33 & 0.00 & 0.00 & 13.33 \\
\hline CD & 1.93 & 1.89 & 1.82 & 32.01 & 40.59 & 53.43 \\
\hline SE(m) & 0.66 & 0.64 & 0.64 & 10.93 & 13.88 & 18.27 \\
\hline
\end{tabular}


Table.2 Pollen viability and longevity of raspberry

\begin{tabular}{|c|c|c|c|}
\hline Date & Total pollen grains & $\begin{array}{c}\text { Pollen grains } \\
\text { stained }\end{array}$ & $\begin{array}{c}\text { Percentage of pollen } \\
\text { grains stained }\end{array}$ \\
\hline $27 / 1 / 16$ & 120 & 120 & $100 \%$ \\
\hline $29 / 1 / 16$ & 450 & 440 & $97.70 \%$ \\
\hline $1 / 2 / 16$ & 120 & 56 & $46.66 \%$ \\
\hline $3 / 2 / 16$ & 80 & 26 & $32.50 \%$ \\
\hline
\end{tabular}

Table.3 Stigma receptivity of raspberry by fruit set method

\begin{tabular}{|l|c|c|c|}
\hline \multicolumn{1}{|c|}{ Age of stigma } & $\begin{array}{c}\text { Number of buds } \\
\text { pollinated }\end{array}$ & $\begin{array}{c}\text { Number of } \\
\text { fruit set }\end{array}$ & $\begin{array}{c}\text { Percentage of fruit } \\
\text { set }\end{array}$ \\
\hline Two days before anthesis & 15 & 5 & $33.33 \%$ \\
\hline One day before anthesis & 15 & 8 & $53.33 \%$ \\
\hline Day of anthesis & 15 & 13 & $86.66 \%$ \\
\hline One day after anthesis & 15 & 9 & $60.0 \%$ \\
\hline Two days after anthesis & 15 & 7 & $46.60 \%$ \\
\hline
\end{tabular}

Table.4 Mode of pollination in raspberry

\begin{tabular}{|l|c|c|c|}
\hline Mode of pollination & $\begin{array}{c}\text { Number of flowers } \\
\text { pollinated }\end{array}$ & Number of fruit set & Percentage of fruit set \\
\hline Self-pollination & 30 & 29 & $96.66 \%$ \\
\hline Cross pollination & 30 & 18 & $60.00 \%$ \\
\hline Natural pollination & 30 & 23 & $76.66 \%$ \\
\hline
\end{tabular}

Plate.1 Pollen germination and pollen tube length

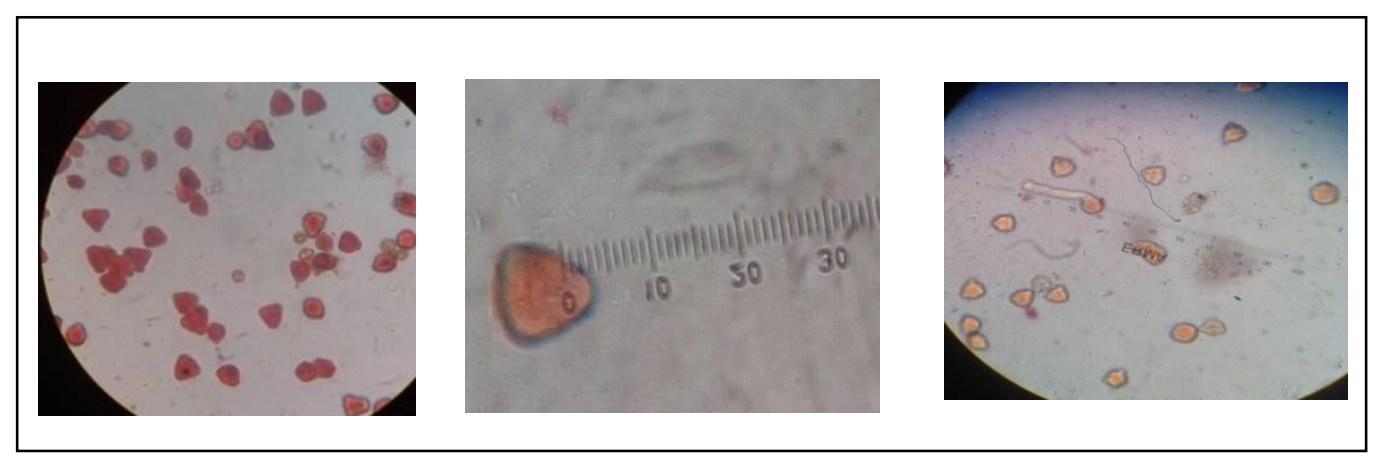

\section{Stigma receptivity}

To find out the receptivity of stigma by visual observation, the stigmas of different age groups varying from 2 days prior up to 2 days after anthesis have been examined daily by hand lens.
The stigma looking shiny, sticky, fresh and attractive were considered to be receptive while dull, dried, faded and brownish stigmas were considered non receptive. The stigmas were green, dark cream in color, less shiny and style length was short two days before anthesis. They were dark cream in color, 
shiny, style was healthy one day after anthesis. On the day of anthesis, stigma turned into brown color, very shiny and sticky with more stigmatic secretion. The ovary size increased with brown colored stigma and stigmatic surface was bilobed one day after anthesis. The basal portion was swollen, style constriction at the middle portion and shininess disappeared.

\section{Fruit set}

In order to study the receptivity of stigma by fruit set method, different flower buds of different age group were emasculated and pollinated with fresh pollen. It is evident from Table 3 that $33.33 \%$ fruit set was observed two days before anthesis while $86.66 \%$ was recorded when stigma were pollinated on the day of anthesis while after one day anthesis the fruit set percentage was $60.10 \%$. The receptivity was almost equally good one day before and one day after anthesis. Kumar (1988) observed the maximum fruit set with cross pollination whereas, minimum fruit set was obtained with hand self-pollination. Abdel et al., (1999) reported highest fruit set under open pollination in cultivar Anna of apple.

\section{Mode of pollination}

To determine the extent of self-fruitfulness, selfing by bagging was done and fruits were assessed. The data presented in Table 4 revealed that the maximum fruit set $(96.66 \%)$ was recorded with self-pollination, followed by natural pollination. The average fruit set in raspberry cultivars under study was $76.66 \%$. Cross pollination showed the minimum fruit set $(60.00 \%)$. Daubeny (1971) found that flowers pollinated only with their own pollen or that with adjacent flowers set nearly 57 to $77 \%$ as open pollinated flowers. Most commercially grown cultivars of red raspberry are self-fertile (Gregor, 1976).
Rajput and Singh (1967) reported that the cross pollination resulted in the highest percentage of fruit set and self-pollination in the lowest fruit set in strawberry cultivars. Shanks (1969) observed that without any additional pollination a berry developed frequently in raspberry, although it was relatively small and had a tuft of unpollinated pistils at its center.

In raspberry plants the pollen size (length $\times$ width) of pollen grains was maximum (177.73 $\mathrm{X} 124.43 \mu)$ in glycerol, followed by water $(173.29 \times 173.29 \mu)$. The highest pollen germination percentage $(36.66 \%)$ and maximum pollen tube length $(284.37 \mu)$ was recorded with $25 \%$ sucrose solution $+0.4 \%$ boric acid solution. The pollens were observed viable up to seven days with $46.66 \%$ germinablity, which decreased rapidly and after three days of storage it remained only $32.50 \%$. The stigma continued to be receptive from two days prior to two days after anthesis. However, the best receptivity of stigma $(86.66 \%)$ has been witnessed on the day of anthesis by the fruit set method. The maximum fruit set $(96.66 \%)$ has been recorded under self-pollination, followed by natural pollination (76.66\%). With these findings of present study it has been suggested that the hybridization should done in raspberry plants when the pollen completely mature and stigma shows maximum receptivity.

\section{References}

Abdel A E, Bahan M K and George R S.1999. Fruit set of low chilling apple cultivars as affected by various pollinizers. Egyptian Journal of Agriculture Research 77(2): 783- 790.

Ali M. 1962. Genetic variability and floral biology of strawberry. M.Sc. Thesis. IARI. New Delhi 211 p. 
Asma B M. 2008. Determination of pollen viability, germination ratios and morphology of eight apricot genotypes. African Journal of Biotechnology 7 (23): 4269-4273.

Bist H S and Sharma S D. 1986. Studies on the pollen, stigma receptivity and pollination in low chilling cultivars of apple (M. domestica Borkh.). Himalayan Journal of Agriculture Research 12(1): 25-32.

Chauhan G C. 1966. Studies on the floral biology and fruit development in strawberry varieties. Journal of American Society for Horticultural Sciences 28: 211-215.

Daubeny H A. 1971. Self-fertility in red raspberry cultivars and selections. Journal of American Society for Horticultural Sciences 96: 588-591.

Focke W O. 1910. Species Ruborum part I. Bibliotheca Botanica 17:1-120.

Gercekcioglu R, Gunes M and Ozkan Y. 2000. A study on determination of pollen quality and pollen production of some fruit cultivars grown in Tokat ecological conditions. Bahce 28(1/2): 54-57.

Gregor S E and Free. 1976. Insect pollination of cultivated crop plants. Agriculture Handbook, 411p.

Kumar R. 1996. Studies on hybridization in apple (Malus x doestica Borkh.) Ph.D. Thesis, Dr. Y. S. Parmar University of Horticulture and Forestry, Nauni, Solan (H.P.) 287 p.

Kumar S. 1988. Studies on the flowering, pollination and fruit set in some new introduction of apple. M.Sc. Thesis, Dr. Y.S. Parmar University of Horticulture and Forestry, Nauni, Solan (H.P.) 205 p.

Otterbacher A G, Hellman E W and Skirvin R M. 1983. Long term storage of raspberry pollen. Journal of Fruit Varieties 37(3): 80-87.

Rajput C B S and Singh J P. 1967. Pollination and fruit setting studies in strawberry. Indian Journal of Horticulture 24:3032.

Shanks C H. 1969. Pollination of raspberries by honeybees. Journal of Apicultural Research 8(1): 19-21.

Stratton L. 1996. The impact and spread of Rubus ellipticus in Ola a Forest Tract Hawaii Volcanoes National Park. Cooperative National Park Resources Studies Unit, University of Hawaii at Manoa, Honolulu. Technical Report: $107 \mathrm{p}$.

Wertheim S J. 1996. Methods for cross pollination and flowering assessment and their interpretation. Acta Horticuturae 423: 237-239.

\section{How to cite this article:}

Neema Pawar, Nidhika Thakur, Manju Negi and Ajay Paliwal. 2017. Studies on Pollen Germination, Pollination and Fruit Set in Raspberry (Rubus ellipticus) under Hilly Conditions of Uttarakhand. Int.J.Curr.Microbiol.App.Sci. 6(9): 3698-3703. doi: https://doi.org/10.20546/ijcmas.2017.609.456 